\title{
Magnetic storm effect on the occurrence of ionospheric irregularities at an equatorial station in the African sector
}

\author{
Olushola Abel Oladipo ${ }^{1,2,}{ }^{\star}$, Torben Schüler $^{3}$ \\ ${ }^{1}$ University of Ilorin, Physics Department, Ilorin, Nigeria \\ ${ }^{2}$ Alexander Von Humboldt Postdoctoral Research Fellow, Institute of Space Technology and Space Application, University \\ FAF Munich, Neubiberg, Germany \\ ${ }^{3}$ Institute of Space Technology and Space Application, University FAF Munich, Neubiberg, Germany
}

\section{Article history}

Received October 30, 2012; accepted June 11, 2013.

Subject classification:

Equatorial ionosphere, Ionospheric irregularities, TEC (Total Electron Content), ROT (Rate of Change of TEC), Magnetic storm.

\begin{abstract}
Large-scale ionospheric irregularities usually measured by GPS TEC fluctuation indices are regular occurrence at the equatorial region shortly after sunset around solar maximum. Magnetic storm can trigger or inhibit the generation of these irregularities depending on the local time the main phase of a particular storm occurs. We studied the effect of nine (9) distinct storms on the occurrence of ionospheric irregularities at Fraceville in Gabon (Lat $=-1.63^{\circ}$, Long $=13.55^{\circ}$, dip lat. $=-15.94^{\circ}$ ), an equatorial station in the African sector. These storms occurred between November 2001 and September 2002. We used TEC fluctuation indices (i.e. ROTI and $\mathrm{ROTI}_{\mathrm{AVE}}$ ) estimated from 30 s interval Rinex data and also we used the storm indices (i.e. Dst, $\mathrm{dDst} / \mathrm{dt}$, and $\mathrm{IMF} \mathrm{B}_{7}$ ) to predict the likely effect of each storm on the irregularities occurrence at this station. The results obtained showed that most of the storms studied inhibited ionospheric irregularities. Only one out of all the storms studied (i.e. September 4, 2002 storms with the main phase on the night of September 7-8) triggered post-midnight ionospheric irregularities. There are two of the storms during which ionospheric irregularities were observed. However, these may not be solely attributed to the storms event because the level of irregularities observed during these two storms is comparable to that observed during previous days before the storms. For this station and for the storms investigated, it seems like a little modification to the use of Aarons categories in terms of the local time the maximum negative Dst occurs could lead to a better prediction. However, it would require investigating many storms during different level of solar activities and at different latitudes to generalize this modification.
\end{abstract}

\section{Introduction}

The ionosphere over the magnetic latitude of about $\pm 20^{\circ}$ centered on the Earth's magnetic equator is referred to as equatorial ionosphere. Post sunset equatorial ionosphere shows electron density irregularities of scale sizes varying from centimeters to kilo- meters and these are generated by plasma instability processes [Rishbeth 1981, Kelley 1985, 1989, Fejer 1996, Abdu 2001]. Shortly after local sunset $E \times B$ vertical drift causes upward lifting of the F-region to an altitude where Rayleigh-Taylor instability processes are favourable for the generation of ionospheric irregularities. Morphology of the equatorial ionospheric irregularities has been studied [e.g., Sobral et al. 2002, Chu et al. 2005, Kintner et al. 2007, Oladipo and Schüler 2012]. Irregularities occurrence has been found to depend on season, geographic location, solar activity, and geomagnetic activities. Ionospheric irregularities usually manifest in amplitude and phase fluctuation of trans-ionospheric radio waves passing through the ionosphere which contains these irregularities. These could cause fading and loss of lock on GPS L1 and L2 with significant impact on GPS positioning accuracy [e.g., Knight et al. 1999, Skone et al. 2001, Doherty et al. 2004, Seo et al. 2011]. It is well known that 400-m smallscale ionospheric irregularities are responsible for amplitude scintillation of the trans-ionospheric radio waves like GNSS signals. These $400-\mathrm{m}$ small-scale irregularities coexist with large-scale ionospheric irregularities [Basu et al. 1999]. Large-scale ionospheric irregularities are the focus of the current study.

The condition described above for the generation of ionospheric irregularities could change drastically during magnetic storm activity. A magnetic storm could enhance the vertical drift of ionization and this could create the right condition for the generation of ionospheric irregularities even during off-season period. Studies on the impact of magnetic storm on the occurrence of ionospheric irregularities have been 
done mainly in the America and Asian sectors of the equatorial region [e.g., Aarons and DasGupta 1984, Dabas et al. 1989, Aarons 1991, Basu et al. 2001, Biktash 2004, Li et al. 2006, Campos de Rezende et al. 2007, Li et al. 2008]. Depending on the local time the main phase of a storm occurs, the storm could trigger or inhibit ionospheric irregularities occurrence. Among the indices that are being used to predict the effect of a storm on the occurrence of ionospheric irregularities are disturbance - storm time (Dst), rate of change of Dst (dDst/dt), and $B_{Z}$ component of the Interplanetary Magnetic Field (IMF $\left.B_{Z}\right)$.

In the current study, we examine nine (9) storms and their consequent effect on large-scale irregularities occurrence at Franceville in Gabon, a station in the equatorial region of the African sector. As mentioned above, previous studies were from the American and Asian sectors. The current study is an attempt to see the likely effect of storms on irregularities occurrence, using GNSS data, at a station in the African sector of the equatorial ionosphere.

\section{Data and analyses}

We have used RINEX data from the IGS network for Franceville in Gabon $\left(\right.$ Lat $=-163^{\circ}$, Long $=13.55^{\circ}$, dip lat. $=-15.94^{\circ}$ ) during 9 distinct storms that occurred between November 2001 and September 2002. Dst values available online at http:/ / wdc.kugi.kyoto-u.ac.jp / dstdir/ and $B_{Z}$ component of the Interplanetary Magnetic Field $\left(I M F B_{Z}\right)$ from high resolution OMNI (HRO) available at ftp://nssdcftp.gsfc.nasa.gov/spacecraft_da ta/omni/high_res_omni/for the period of these storms were also used.

To obtain relative TEC, we have used the leveled carrier phase measurement of TEC, i.e. the so called carrier phase to code leveling. Because phase measurements are sometimes affected by or subjected to cycle slips, we used Blewitt [1990] algorithm for detection and correction of cycle slips in the phase measurements. The algorithm describes the procedure on how to detect and correct cycle slip in phase measurements using both the wide lane combination and the ionospheric combination methods. The algorithm employs the use of undifferenced, dual frequency carrier phase measurements and a smoothly varying ionospheric electron content. Full description of this Algorithm can be found in Blewitt [1990]. Butterworth filter of order 4 was used to remove the trends from the data. Butterworth filter of order 4 is a filter developed by Butterworth [1930]. The full description of the Butterworth filter can be found in Butterworth [1930]. Two TEC fluctuation indices (i.e. ROT derived indices) in equations 1 and 2 are used for this study.
$R O T I=\sqrt{\left\langle R O T^{2}\right\rangle-\langle R O T\rangle^{2}}, R O T=\frac{\Delta T E C}{\Delta t}$

$\operatorname{ROTI}_{A V E}(0.5 \mathrm{hr})=$

$\frac{1}{n \operatorname{Sat}(0.5 \mathrm{hr})} \sum_{n}^{n S a t} \sum_{i}^{k} \frac{\operatorname{ROTI}(n, 0.5 \mathrm{hr}, i)}{k}$

Where $n$ is the satellite number, $0.5 \mathrm{hr}$ is half an hour $(0,0.5,1, \ldots 23.5,24 \mathrm{UT}), i$ is the 5 minutes section within half an hour $(i=1,2,3,4,5,6), n \operatorname{Sat}(0.5 \mathrm{hr})$ is the number of satellites observed within half an hour and $k$ is the number of ROTI values available within half an hour for a particular satellite. ROTI (after Pi et al. [1997]) values are for a single satellite while $R O T I_{A V E}$ (after Oladipo and Schüler [2013]) gives 30 minutes average values for all satellites and the values are valid over a station.

Using GNSS data to derive TEC fluctuation indices, the choice of elevation cut-off mask is very important so as not to mix multipath effect with ionospheric irregularities. To screen out multipath effects elevation cut-

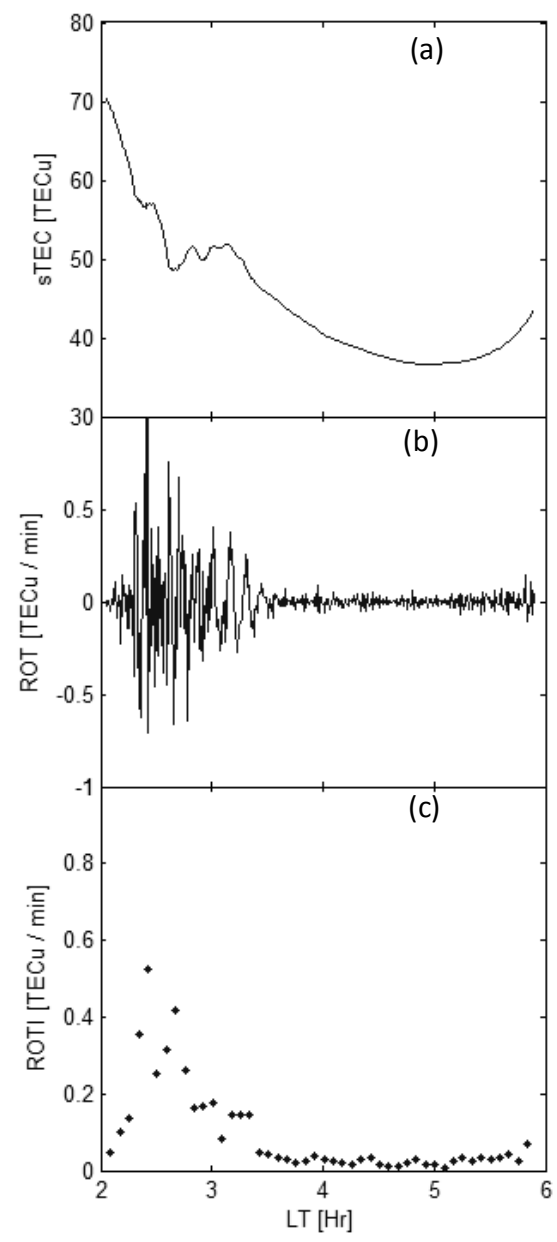

Figure 1. Large-scale irregularities as manifested in (a) Relative sTEC (uncalibrated) in TECu, (b) ROT in TECu/min, and (c) ROTI index after Pi et al., 1997 in TECu/min for PRN 9 at Fraceville on May 22, 2002 (1 TEC $u=10^{16}$ electrons $\mathrm{m}^{-2}$ ). Elevation cut-off mark of 25 degree was used. The plots indicate depletion of ionization (shown in a) due to large scale ionospheric irregularities and these irregularities are captured by ROT and ROTI indices. 
off mask of 25 degrees was used in the current study.

Figure 1 shows a typical example of large-scale ionospheric irregularities as captured by TEC depletion (Figure 1a) and the corresponding ROT (Figure 1b) and the phase fluctuation index ROTI (Figure 1c). The irregularities as shown in this figure is observed for satellite with PRN 9 around 03.00 LT at Fraceville and the two indices (i.e. ROT and ROTI) really captured the level of depletion as observed in TEC values.

\section{Results and discussions}

We have studied the effect of nine (9) distinct storms that occurred between November 2001 and September 2002 on the occurrence of ionospheric irregularities at Fraceville. Some of these storms have more than one main phase i.e. storm(s) that occurred during the recovery phase of another storm. However, three selected storms out of all the storms studied are presented in detail in Sections 3.1 to 3.3 while the summary of all the storms studied and discussions are presented in Section 3.4.

\subsection{Magnetic storm of November 5-9, 2001}

Figure 2 shows the panel plots for the storm of November 5-9, 2001 at Fraceville for (a) Dst in $n T$, (b) rate of change of Dst (dDst/dt in $n T / h)$, (c) IMF $B_{z}$ in $n T$, (d) $R_{\text {OTI }}$ AVE in TEC/min, and (e) ROTI in TEC/min. The vertical dashed line indicates the time in UT when minimum dDst/dt occurred. It is important to mention here that Figure 2e is the plot of ROTI values obtained for all the observed satellites for the day. As shown in Figure $2 \mathrm{a}$, the storm started with sudden commencement at 12:00 UT on November 5 and was followed by an initial phase which lasted for about 7 hours (i.e. from 12:0019:00 UT, November 5). The main phase which lasted for about 13 hours was from $\sim 20$ :00 UT, November 5 to 09:00 UT, Nov. 6, while the recovery phase lasted for about 3 days (i.e. November 7-9). The maximum negative Dst value was $-292 n T$ and it occurred at 07:00 UT (08:00 LT). There was a data gap in IMF $B_{Z}$ on November 6, 2001, the day the main phase of the storm occurred. For this storm, maximum negative $d D s t / d t$ of $-168 n \mathrm{~T} / \mathrm{h}$ was recorded at around 04:00 UT (05:00 LT).

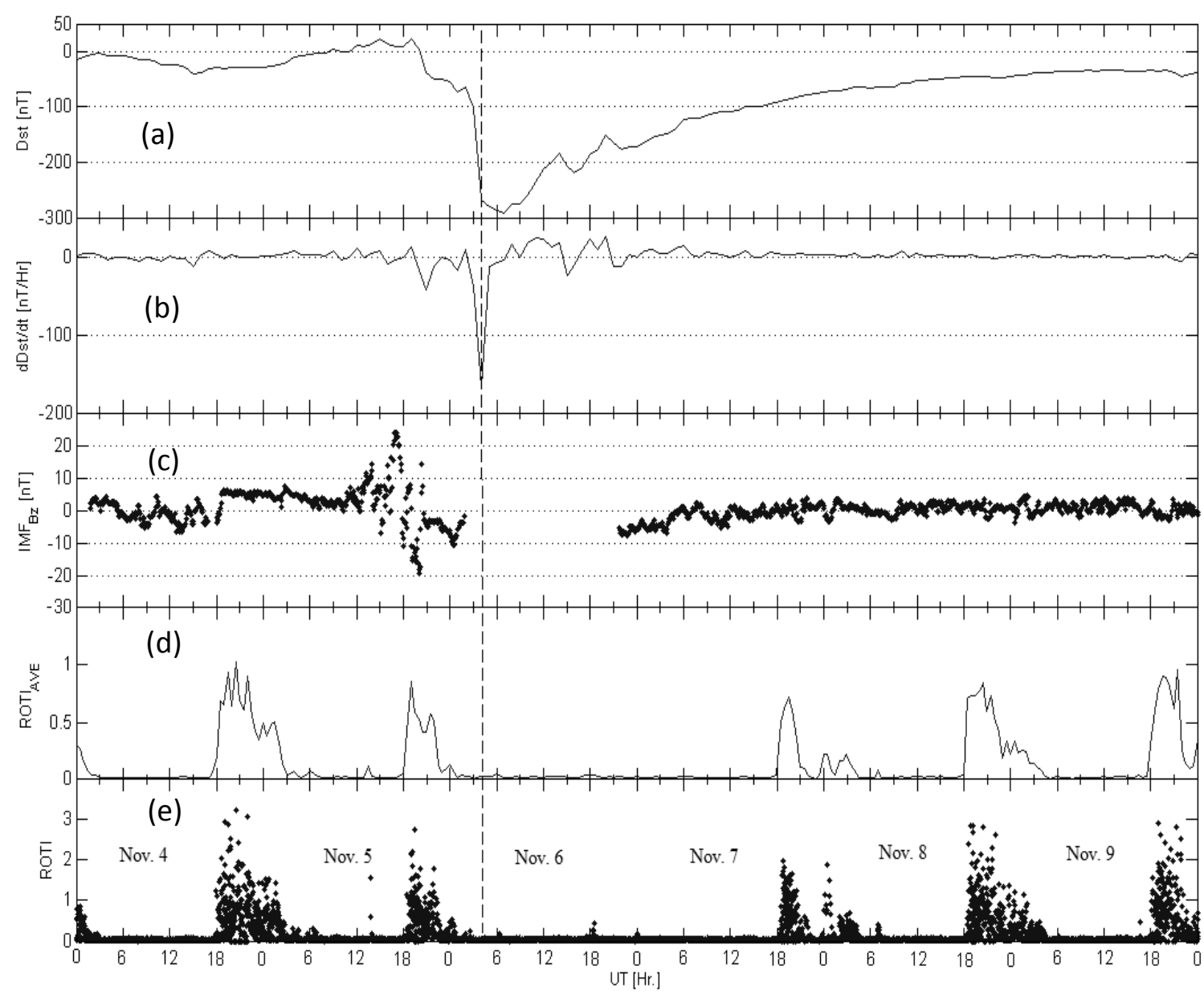

Figure 2. Effect of November 5-9, 2001 storm on ionospheric irregularities occurrence at Franceville, Gabon. The plots are for (a) Dst in $n T$ (b) rate of change of Dst (dDst/dt in $n T / h$ ), (c) $I M F_{B Z}$ in $n T$, (d) $R O T I_{A V E}$ in TEC/min, and (e) ROTI in TEC/min. The vertical dashed line indicates the time in UT when maximum negative $d D s t / d t$ was observed. 
As indicated in Figure 2d,e this storm inhibited irregularities occurrence during the night of November 6-7.

\subsection{Magnetic storm of April 17-22, 2002}

Figure 3 shows the panel plots for the April 17-22, 2002 storm. The plot is similar to Figure 2. The vertical dashed lines indicate the time in UT when maxima negative values of $d D s t / d t$ were observed. As shown in 3 (a), magnetic storm of April 17-22, 2002 has no sudden commencement. The storm has about four main phases
(Figure 3c) turned southward more than five times during the main phases of this storm. For each of these southward, $I M F B_{Z}$ values remain negative for a fairly long period of time. For the four days that the main phases of this storm occurred, ionospheric irregularities were inhibited as shown in Figure 3d,e.

\subsection{Magnetic storm of September 3-9, 2002}

Similar to Figures 2 and 3, Figure 4 shows the panel plots for the September 3-9, 2002 storm at Franceville.

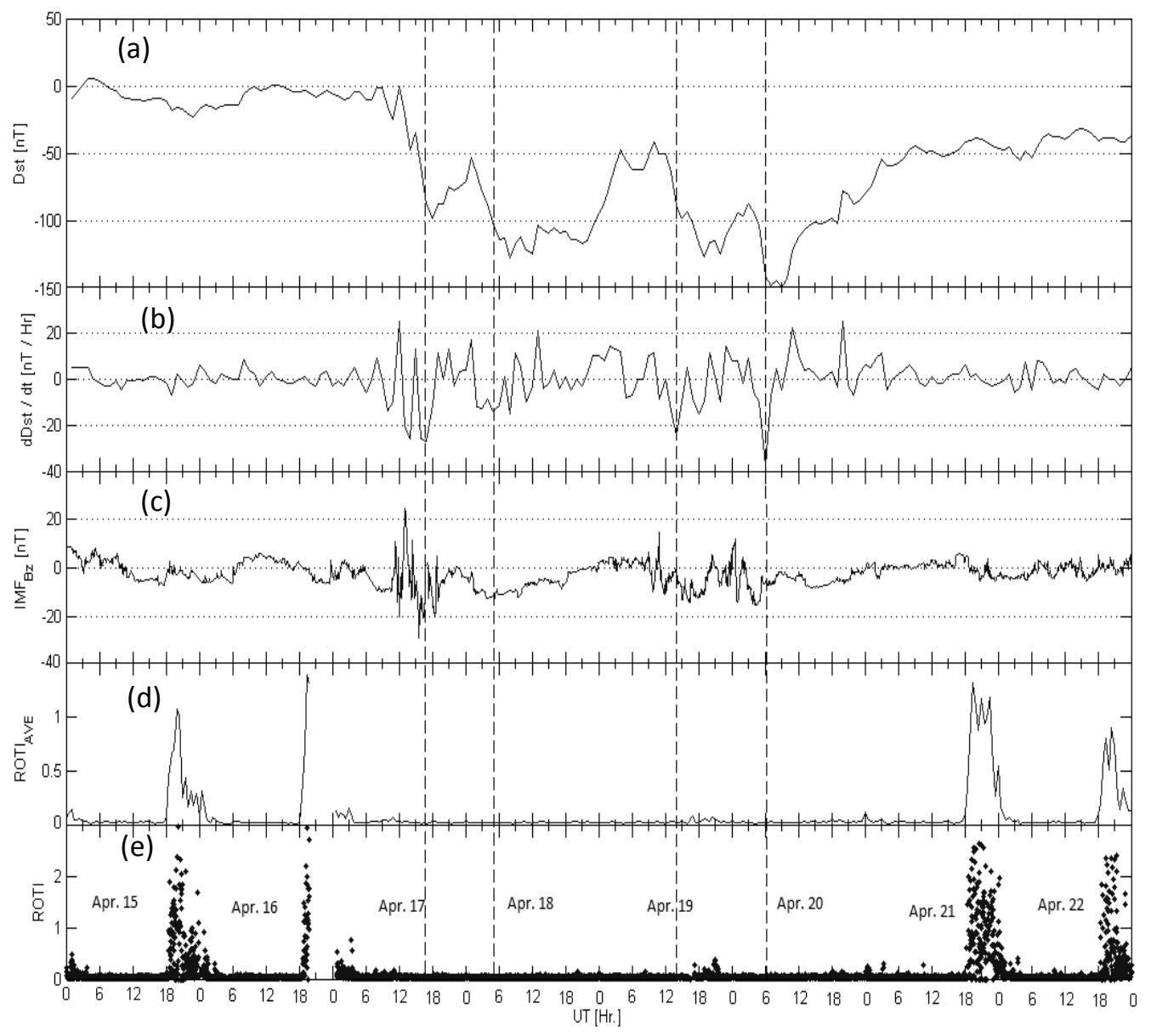

Figure 3. Effect of April 17-22, 2002 storm on ionospheric irregularities occurrence at Franceville, Gabon. The plots are for (a) Dst in $n T$ (b) rate of change of $D s t\left(d D s t / d t\right.$ in $n T / h$ ), (c) IMF $B_{Z}$ in $n T$, (d) $R O T I_{A V E}$ in $T E C / \mathrm{min}$, and (e) ROTI in TEC/min. The vertical dashed lines indicate the time in UT when maxima negative $d D s t / d t$ were observed.

which covers about four days (i.e. April 17-20) and has its maximum on April 20 at 09:00 UT (10:00 LT at Franceville) with Dst value of $-149 n T$. Each of these four main phases has its maximum at 18:00 UT (19:00 LT) on April 17 with Dst value of $-98 n$, at 12:00 UT (13:00 LT) on April 18 with Dst value of $-124 n T$, at 19:00 UT (20:00 LT) on April 19 with Dst value of $-126 n T$, and at 09:00 UT (10:00 LT) on April 20 with Dst value of $-149 n T$. The $\mathrm{dDst} / \mathrm{d} t$ value (Figure $3 \mathrm{~b}$ ) followed similar pattern as Dst during the storm with more than four minima values that nearly coincided with that of Dst values. IMF $B_{Z}$
The storm of September 3-9, 2002, with sudden commencement at $\sim 05$ UT on September 3 , has an initial phase which lasted for about 20 hours (i.e. from $\sim$ 06:00 UT on September 3 to $\sim$ 02:00 UT on September 4) and it has two main phases. The two main phases occurred on September 4 and on September 7-8 and their negative maximum Dst values are $-109 n \mathrm{~T}$ at 06:00 UT (07:00 LT) and $-181 n T$ at 01:00 UT on September 8 (02:00 LT) respectively. The vertical dashed lines indicate the time in UT when maxima negative $d D s t / d t$ were observed. For this first storm, $I M F B_{Z}$ (Figure 4c) turned southward 


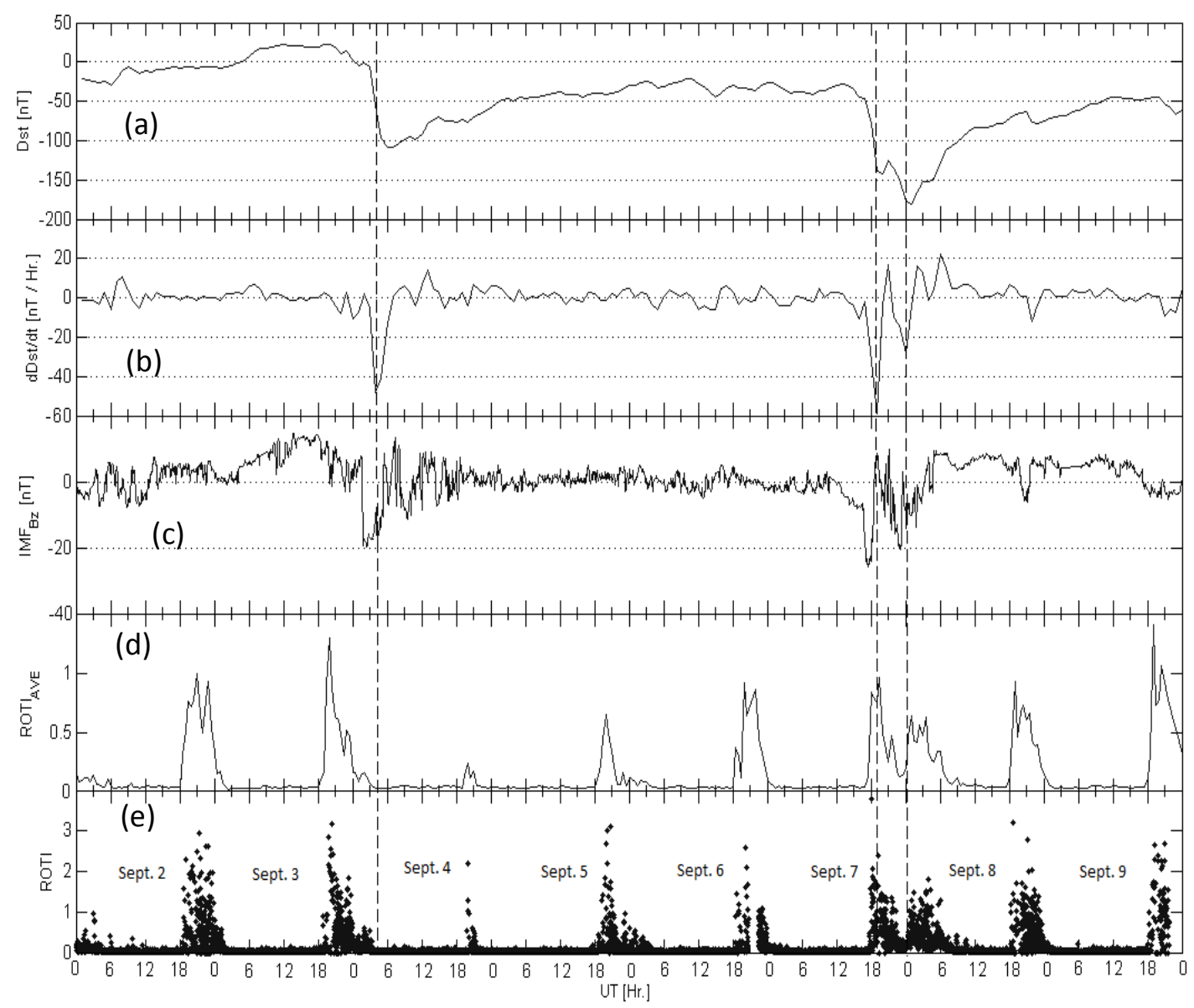

Figure 4. Effect of September 3-9, 2002 storm on ionospheric irregularities occurrence at Franceville, Gabon. The plots are for (a) Dst in $n T$ (b) rate of change of $D s t$ (dDst/dt in $n T / h$ ), (c) $I M F_{B Z}$ in $n T$, (d) $R O T I_{A V E}$ in $T E C / \mathrm{min}$, and (e) ROTI in TEC/min. The vertical dashed lines indicate the time in UT when maxima negative $d D s t / d t$ were observed.

twice on September 4 the day the first main phase occurred. However, the maximum negative $d D s t / d t$ is only observed once at around 05:00 UT (06:00 LT) and the value is $-24 n T / H r$. The effect of this storm is an inhibition of ionospheric irregularities on the night of September 4-5. Similarly for the second storm, IMF $B_{Z}$ turned southward twice on September 7 the day the second main phase occurred. These were also observed in $d D s t / d t$ (Figure $4 \mathrm{~b}$ ) with maximum negative values at around 19:00 UT (20:00 LT) and 00:00 UT (01:00 LT) and the values are $-59.0 \mathrm{nT} / \mathrm{Hr}$ and $-28.0 \mathrm{nT} / \mathrm{Hr}$ respectively. This particular storm triggered post-midnight ionospheric irregularities on the night of September 78 as shown in Figure 4d,e.

\subsection{Summary of results and discussions}

Table 1 shows the summary of the results obtained for all the storms studied. As indicated in the table, most of the storms studied inhibited ionospheric irregularities occurrence at Fraceville. Only one out of all the storms studied (i.e. September 4, 2002 storms with the main phase on September 7-8) triggered post-midnight ionospheric irregularities. There are two of the storms (i.e. storms of February 6 and August 21, 2002) during which ionospheric irregularities were observed. However, these may not be solely attributed to the storms event because the level of irregularities observed during these two storms is comparable to that observed during previous days before the storms.

Previous results have shown that the effect of a magnetic storm on the occurrence of ionospheric irregularities at a particular station depends on the local time of the day at which the main phase on the storm occurs. The general consensus is that a magnetic storm can trigger (or inhibit) ionospheric irregularity occurrence when the storm enhances (or reduces) the $E \times B$ vertical drift responsible for the upward lifting of the Fregion to an altitude where Rayleigh-Taylor instability processes are favourable for the generation of ionospheric irregularities. Different researchers have put forward different explanations, using different indices, for the likely effect of storm on the occurrence of ionospheric irregularities. For example, the disturbance storm time (Dst) variations have been considered to be the best criteria to determine the development of the equatorial irregularities during a storm [Dabas et al. 


\begin{tabular}{|c|c|c|c|c|}
\hline Storm & Time of SSC, (DOY) & $\begin{array}{l}\text { min. Dst (Time in UT), DOY } \\
(L T=U T+1)\end{array}$ & min. (Time in UT), DOY & Irregularities Occurrence \\
\hline $\begin{array}{l}\text { Nov. 05, } 2001 \\
\text { Feb. 02, } 2002 \\
\text { Feb. 06, } 2002 \\
\text { Mar. 23, } 2002\end{array}$ & $\begin{array}{c}\text { 12:00 UT (309) } \\
\text { 00:00 UT (033) } \\
\quad- \\
\text { 12:00 UT (082) }\end{array}$ & $\begin{array}{l}-292(07: 00), 310 \\
-86(10: 00), 033 \\
-82(21: 00), 036 \\
-100(10: 00), 083 \\
-94(17: 00), 083\end{array}$ & $\begin{array}{c}-168(04: 00), 310 \\
-25(05: 00), 033 \\
-28(21: 00), 036-17 \\
(09: 00), 083 \\
-9(14: 00), 083\end{array}$ & $\begin{array}{l}\text { inhibit } \\
\text { inhibit } \\
\text { no effect }\end{array}$ \\
\hline Apr. 17, 2002 & - & $\begin{array}{l}-98 \text { (18:00), } 107 \\
-124(19: 00), 108 \\
-126(09: 00), 109 \\
-149 \text { (09:00), } 110\end{array}$ & $\begin{array}{l}-27(17: 00), 107 \\
-14(05: 00), 108 \\
-24(14: 00), 109 \\
-38(08: 00), 110\end{array}$ & $\begin{array}{l}\text { inhibit } \\
\text { inhibit } \\
\text { inhibit } \\
\text { inhibit }\end{array}$ \\
\hline May 11, 2002 & 11:00 UT (131) & $-110(20: 00), 131$ & $-41(17: 00), 131$ & inhibit \\
\hline May 23, 2002 & 10:00 UT (143) & $-109(18: 00), 143$ & $-83(12: 00), 232$ & inhibit \\
\hline Aug. 21, 2002 & 20:00 UT (230) & $\begin{array}{l}-47(02: 00), 231 \\
-71(00: 00), 232 \\
-104(03: 00), 233\end{array}$ & $\begin{array}{l}-24(00: 00), 131 \\
-12(00: 00), 232 \\
-21(00: 00), 233\end{array}$ & $\begin{array}{l}\text { no effect } \\
\text { no effect } \\
\text { no effect }\end{array}$ \\
\hline Sept. 03, 2002 & 05:00 UT (246) & $\begin{array}{l}-109(06: 00), 247 \\
-181(01: 00), 251\end{array}$ & $\begin{array}{l}-48(05: 00), 247 \\
-59(19: 00), 250 \\
-28(00: 00), 251\end{array}$ & $\begin{array}{l}\text { inhibit } \\
\text { trigger post mind-night }\end{array}$ \\
\hline
\end{tabular}

Table 1. Summary of the results obtained on the effect of magnetic storms on ionospheric irregularities occurrence at Fraceville

1989, Aarons 1991, Aarons et al. 1997]. As pointed out by Aarons [1991], if the maximum ring current energy, as indicated by maximum negative value, occurs during the midnight to post-midnight time period irregularities would be generated. If the maximum negative Dst, the period before recovery set in, occurs in the early afternoon, irregularities would be inhibited. If the maximum occurs around sunset or shortly after sunset, then there would be no effect on the generation of irregularities that night. These have led to three categories based on the local time that maximum negative Dst value occurs; 00-06 LT (generation of irregularities), 10-16 LT (inhibition of irregularities) and 18-22 LT (no effect). When these categories by Aarons [1991] based on the local time the maximum negative of Dst occurred were used in the current study, we observed that only 5 out of 15 main phases studied could be predicted correctly using these categories. It is very important to note that when we have complex shapes in Dst variations, the Dst category conception cease to have its conventional meaning. We observed complex shapes in Dst variation for some of the storm studied but there are some without complex variation in Dst that are still predicted wrongly. Also it is important to note that these categories by
Aarons [1991] left out some hours of the day around sunrise, sunset and before midnight. As observed in this study, some of the main phases had their maximum negative Dst recorded during these hours. We then applied the categories by Dabas et al. [1989], i.e. 06-18 LT (inhibition of irregularities), 18-00 LT (no effect) and 0006 LT (generation of irregularities). Nine (9) out of the 15 main phases could be predicted correctly, three fell close to the boundary, while the remaining four could not be explained based on these categories.

Li et al. [2008], instead of using Dst, gave three categories which are similar to those of Aarons [1991] based on the local time the maximum negative value of dDst/dt occurred i.e. 00-06 LT (inhibition of irregularities), 10-16 LT (no effect) and 18-22 LT (generation of irregularities). We observed that only 5 out of 15 main phases studied fit in into these categories. Another index being used is $I M F B_{Z}$. The southward turning of $I M F B_{Z}$ (i.e. when $I M F B_{Z}$ is negative) usually signals the transfer of energy, mass, and momentum from the solar wind flow to the magnetosphere. The negative $I M F B_{Z}$ is believed to enhance $E x B$ vertical drift while positive $I M F$ $B_{Z}$ does the opposite. A good example of this is the storm of September 2002. During the second main 
phase which occurred on the night of September 7-8, $I M F B_{Z}$ turned negative and post-midnight irregularities was observed.

\section{Conclusions}

We have studied the effect of nine (9) different storms on the occurrence of ionospheric irregularities at Fraceville in Gabon, an equatorial station in the African sector. These storms occurred between November 2001 and September 2002 which was a period around the last solar maximum. We used TEC fluctuation indices (i.e. ROTI and $R O T I_{A V E}$ ) estimated from $30 \mathrm{~s}$ interval Rinex data and these give the level of large scale ionospheric irregularities. These irregularities of course are known to coexist with the 400-m small-scale irregularities responsible for the amplitude scintillation of GNSS signals. We also used three storm indices (Dst, $d D s t / d t$, and IMF $B_{Z}$ ) for this study. Out of all the storms studies only one triggered post-midnight ionospheric irregularities, two distinct storms with four main phases had no effect, while the remaining storms (or main phases) inhibited ionospheric irregularities at Franceville. For this station and for the storms investigated, it seems more plausible to use a modified Aarons [1991] categories (i.e. 06-18 LT (inhibition of irregularities), 18-00 LT (no effect) and 00-06 LT (generation of irregularities) based on the local time the maximum negative Dst occurs to predict the likely effect of a storm on the occurrence of ionospheric irregularities. However, a comprehensive study, involving many storms during different level of solar activities and at different latitudes, would be required to generalize this modification.

Acknowledgements. The authors would like to thank the IGS community (International GNSS Service) for granting access to the dual-frequency GPS data on the IGS network used in this study. Also we acknowledgement the Space Physics Data Facility (SPDF) and National Space Science Data Center (NSSDC) for making high resolution OMNI (HRO) data publicly available for scientific use. O.A. Oladipo would like to appreciate Alexander von Humboldt foundation for supporting his postdoctoral research fellowship in Germany during which the work presented in this paper was carried out.

\section{References}

Aarons, J. and A. DasGupta (1984). Equatorial scintillations during the major magnetic storm of April 1981, Radio Sci., 19, 731-739.

Aarons, J. (1991). The role of the ring current in the generation or inhibition of equatorial F-layer irregularities during magnetic storms, Radio Sci., 26, 1131-1149.

Aarons, J., M. Mendillo and R. Yantonsca (1997). GPS phase fluctuations in the equatorial region during sunspot minimum, Radio Sci., 32, 1535-1550.
Abdu, M. A. (2001). Outstanding problems in the equatorial ionosphere-thermosphere electrodynamics relevant to spread F, J. Atmos. Terr. Phys., 63, 869-884.

Basu, S., K. M. Groves, J. M. Quinn and P. Doherty (1999). A comparison of TEC Fluctuations and scintillations at Ascension Island, J. Atmos. Sol. Terr. Phys. 61, 1219-1226.

Basu, S., S. Basu, C.E. Valladares, H. C.Yeh, S. Y. Su, E. Mackenzie, P. J. Sultan, J. Aarons, F.J. Rich, P. Doherty, K. M. Groves and T. W. Bullett (2001). Ionospheric effects of major magnetic storms during the international space weather period of September and October 1999: GPS observations, VHF/UHF scintillations, and in situ density structures at middle and equatorial latitudes, J. Geophys. Res., 106 (A12), 30389-30414.

Biktash, L.Z. (2004). Role of the magnetospheric and ionospheric currents in the generation of the equatorial scintillations during geomagnetic storms, Annales Geophysicae, 22, 3195-3202.

Blewitt, G. (1990). An automatic editing algorithm for GPS data, Geophys, Res. Lett., 17 (3), 199-202.

Butterworth, S. (1930). On the Theory of Filter Amplifiers, Experimental Wireless and the Wireless Engineer, 7, 536-541.

Campos de Rezende, L.F., E. Rodrigues de Paula, I. Stacarini Batista, I. Jelinek Kantor and M. Tadeu de Assis Honorato Muella (2007). Study of Ionospheric irregularities during intense magnetic storm, Revista Brasileria de Geofisica, 25 (Suppl. 2), 151-158.

Chu, F. D., J. Y. Liu, H. Takahashi, J. H. A. Sobral, M. J. Taylor and A. F. Medeiros (2005). The climatology of ionospheric plasma bubbles and irregularities over Brazil, Annales Geophysicae, 23, 379-384.

Dabas, R. S., D. R. Lakshmi and B. M. Reddy (1989). Effect of geomagnetic disturbances on VHF nighttime scintillation activity at equatorial and low latitudes, Radio Sci., 4, 563-573.

Doherty P.H., S. H. Delay, C. E. Valladares and J. A. Klobuchar (2004). Ionospheric scintillation effects on GPS in the equatorial and auroral regions, Navigation ISSN 0028-1522 CODEN NAVIB3, 50 (4), 235245.

Fejer, B.G. (1996). Natural Ionospheric Plasma Waves, In: Kohl, H., Ruster, R., Schlegel, K., Modern Ionospheric Science.

Kelley, M. C. (1985). Equatorial spread F: some recent results and outstanding problems, J. Atmos. Terr. Phys., 47, 745-752.

Kelley, M. C. (1989). The Earth's Ionosphere Plasma Physics and Electrodynamics, Academic Press.

Kintner, P.M., B. M. Ledvina and E. R. de Paula (2007). GPS and ionospheric scintillations, Space Weather, 
5, S09003; doi: 10.1029/2006SW000260.

Knight, M., M. Cervera and A. Finn (1999). A comparison of predicted and measured GPS performance in an ionospheric scintillation environment, In: ION GPS-99, Proceedings of the 12th International Technical Meeting of the Satellite Division of the Institute of Navigation, Nashville, TN, United States, 14-17, 1437-1450.

Li, G., B. Ning, W. Wan and B. Zhao (2006). Observations of GPS ionospheric scintillations over Wuhan during geomagnetic storms, Annales Geophysicae, 24, 1581-1590.

Li, G., B. Ninga, B. Zhaoa, L. Liua, J. Y. Liu and K. Yumoto (2008). Effects of geomagnetic storm on GPS ionospheric scintillations at Sanya, J. Atoms. Sol. Terr. Phys., 70, 1034-1045.

Mendillo, M., B. Lin and J. Aarons (2000). The application of GPS observations to equatorial aeronomy, Radio Sci., 35 (3), 885-904.

Oladipo, O. A. and T. Schüler (2013). Equatorial ionospheric irregularities using GPS TEC derived index, J. Atmos. Sol. Terr. Phys., 92, 78-82.

Pi, X., A. J. Mannucci, U. J. Lindqwister and C. M. Ho (1997). Monitoring of global ionospheric irregularities using the worldwide GPS network, Geophys. Res. Lett., 24, 2283-2286.

Rishbeth, H. (1981). The F-region dynamo, J. Atmos. Terr. Phys., 43, 387.

Seo J., T. Walter and P. Enge (2011). Availability Impact on GPS Aviation due to Strong Ionospheric Scintillation, IEEE Transactions on Aerospace and Electronic Systems, 47 (3), 1963-1973.

Skone S., K. Knudsen and M. de Jong (2001). Limitations in GPS receiver tracking performance under ionospheric scintillation conditions, Phys. Chem. Earth (A), 26 (6-8), 613-621.

Sobral, J. H. A., M. A. Abdu, H. Takahashi, M. J. Taylor, E. R. de Paula, C. J. Zamlutti, M. G. de Aquino and G. L. Borba (2002). Ionospheric plasma bubble climatology over Brazil based on 22 years (1977-1998) of $630 \mathrm{~nm}$ airglow observations, J. Atmos. Sol. Terr. Phys., 64, 1517-1524.

\footnotetext{
${ }^{\star}$ Corresponding author: Olushola Abel Oladipo,

University of Ilorin, Physics Department, Ilorin, Nigeria; Institute of Space Technology and Space Application, University FAF Munich, Neubiberg, Germany;

email: ooladipo@unilorin.edu.ng; olushola.oladipo@unibw.de. 